\title{
ANALYTICAL VALIDATION FORMULAS FOR BEST ESTIMATE CALCULATION IN TRADITIONAL LIFE INSURANCE
}

\author{
SIMON HOCHGERNER, FLORIAN GACH
}

\begin{abstract}
Within the context of traditional life insurance, a model-independent relationship about how the market value of assets is attributed to the best estimate, the value of in-force business and tax is established. This relationship holds true for any portfolio under run-off assumptions and can be used for the validation of models set up for Solvency II best estimate calculation. Furthermore, we derive a lower bound for the value of future discretionary benefits. This lower bound formula is applied to publicly available insurance data to show how it can be used for practical validation purposes.
\end{abstract}

\section{INTRODUCTION}

Per 1 January 2016 the European Union has implemented a new insurance regulation scheme called Solvency II. The own funds in this regime, essentially, equal the excess of the market value of assets over the market value of liabilities. The legal basis for calculating market values in accordance with Solvency II is Art. 88 in [13]. One of the reasons that this is a difficult matter is that insurance liabilities are not traded in an active market. See [20, 19, 22, 8, 17] for more information and a discussion.

In the context of traditional life insurance products, with a well-defined profit sharing mechanism, the market value of liabilities is dominated by the so-called best estimate. Indeed, for the aggregated Austrian market we have, per year end 2016, the following situation (in billion EUR):

\begin{tabular}{l|c}
\hline Technical provisions - life (excluding health and index-linked and unit-linked) & 59 \\
\hline Best estimate & 58 \\
\hline Risk margin & 1 \\
\hline
\end{tabular}

That is, the risk margin is only about $1.8 \%$ of the best estimate. For Germany we have a similar situation:

\begin{tabular}{l|c}
\hline Technical provisions - life (excluding health and index-linked and unit-linked) & 909 \\
\hline Best estimate & 894 \\
\hline Risk margin & 15 \\
\hline
\end{tabular}

Again, the risk margin amounts to $1.6 \%$ of the best estimate. All these numbers are taken from the EIOPA insurance statistics web-site [9].

Date: June 27, 2019.

Key words and phrases. Solvency II, Best Estimate, Asset Liability Management, Market Consistent Valuation. 
Thus, own funds of the company strongly depend on the value of the best estimate $(B E)$. Unfortunately, best estimate calculation for traditional life insurance books is a very difficult problem and its result generally subject to considerable modelling uncertainty.

To get an idea of the impact of errors, or uncertainty, of $B E$ calculation, consider the following, not untypical, sand-box life insurance example in Table 1. In fact, these numbers

\begin{tabular}{l|c}
\hline Best Estimate & 3 '864 \\
\hline Eligible Own Funds & 572 \\
\hline Solvency Capital Requirement $(S C R)$ & 292 \\
\hline
\end{tabular}

TABLE 1.

are not arbitrary, but represent (in billion EUR) the European aggregate values taken from [14] for the base-line scenario. The corresponding solvency ratio is thus $572 / 292 \cong 196 \%$. There are two (not unrelated) points to be made here: The eligible own funds are one order of magnitude smaller than the technical provisions, which we have identified with the best estimate (by disregarding the much smaller risk margin) for the sake of exposition. Secondly, an increase of the best estimate by only $1 \%$ would result in a decrease of solvency ratio by $0.01 \cdot 3^{\prime} 864 / 292 \cong 13$ percentage points. An increase by $10 \%$ would yield a solvency ratio below $100 \%$, i.e. insolvency. Here we assumed the $S C R$ to remain unchanged by an increase in $B E$. In reality the $S C R$ would increase with increasing $B E$, whence the resulting solvency ratio would be even smaller.

In fact, [14] has considered mainly, but not exclusively, life insurance companies. If one were to include only traditional life insurance books in the sample, the impact of best estimate changes on solvency ratios should be expected to be even stronger.

We mention these numbers in order to stress the importance of reliable and stable best estimate calculation.

In order to calculate a best estimate for traditional life insurance in accordance with Solvency II regulation, one has to set up an asset liability model which generates cash-flows according to local generally accepted accounting principles. In particular, such a model has to keep track of book and market values of assets under management and generate a return on assets that is in line with realistic management actions. Furthermore, a stochastic economic scenario generator is needed to model the asset portfolio and the relevant discount rates.

It is therefore not surprising that there are no closed formulas to calculate best estimate liabilities associated to traditional life insurance contracts. Let us remark in this context, that one of the outstanding features of the traditional life insurance business is that there exists a mechanism of profit sharing between the firm's surplus and the policy holder (see [12]).

The goal of this paper is to present two results, Propositions 2.2 and 3.4, which provide simple and effective tools for best estimate validation. These validation tools are the next best thing to having a closed formula for best estimate calculation in the sense that they are analytical and model-independent. That is, they have to hold for any best estimate calculation in the context of life insurance with profit sharing - as long as certain assumptions are met. These assumptions are explicitly spelled out and subsequently discussed in Sections 2.C and 3.D. Let us remark that these assumptions are tailor-made to the Austrian and German life 
insurance markets. We have not attempted a comprehensive study concerning the validity of the assumptions for other European markets.

As an example, we apply the estimation formula of Proposition 3.4 to publicly available data of the Allianz Lebensversicherungs AG.

Conclusions concerning our results are discussed in Section 4.

Acknowledgements. We thank the anonymous reviewers for their detailed and helpful input.

Disclaimer. The views expressed in this article reflect the authors' personal opinions and do not necessarily coincide with those of the Austrian Financial Market Authority (FMA).

\section{A BASIC EQUATION OF TRADITIONAL LIFE INSURANCE VALUATION}

2.A. Traditional life insurance company. We consider a company selling traditional life insurance business. Traditional means in this context that there is a procedure of profit participation which is defined by local generally accepted accounting principles. The set of insurance contracts in the company's liability book shall be denoted by

$$
\mathcal{X} \text {. }
$$

Hence each $x \in \mathcal{X}$ corresponds to an individual policy holder. The types of contracts we consider in this context are those of [12, Chapters 3 and 4]: life insurance and life annuities, subject to profit participation. Let us assume:

Assumption 2.1. The liability book consists of two items:

(1) $T R$, the technical reserves;

(2) $S F$, the surplus fund.

The technical reserves are made up of the individual statutory reserves, by which we mean the contract specific reserves $T R_{x}$ with respect to local generally accepted accounting standards. Thus to each insurance contract there corresponds a well-defined technical reserve $T R_{x}$, and $T R$ is the sum of all the individual reserves. We emphasize that the technical reserves $T R_{x}$ are assumed to be calculated as explained by [12], that is, with respect to a constant technical interest rate and with respect to prudentially chosen safety loadings. The surplus fund, on the other hand, is an additional balance sheet item that belongs to the collection of insured viewed as a whole, whence it belongs to the liability book. However, it cannot be assigned to any individual contracts. Its purpose is to smoothen the declaration of profit participation over time.

The book values

$$
B V(T R)=\sum_{x \in \mathcal{X}} B V\left(T R_{x}\right)
$$

and $B V(S F)$ of $T R$ and $S F$ of the technical reserves and of the surplus fund, respectively, are well-defined balance sheet items in the realm of the local generally accepted accounting principles (see $[4, \S 144]$ for the Austrian version). The objective of this section is to derive a general and model-independent relation for the associated best estimate, which is an item of the company's Solvency II balance sheet. This derivation depends on a number of assumptions which are discussed below in Subsection 2.C. 
2.B. The basic equation. We work on a discrete time grid $0, \ldots, T$. In practice time will be measured in years and $T$ will be the time until the run-off of (a sufficiently large percentage of) the portfolio. Usually $T$ is 60 years or even more. All our stochastic processes are assumed to be adapted to some underlying filtered probability space satisfying the usual assumptions.

Assume we have fixed an interest rate model with corresponding bank account numeraire

$$
B_{t}, \quad t=0, \ldots, T, \quad B_{0}=1 .
$$

Let $\mathbb{Q}$ be the risk neutral martingale measure associated to our interest rate model or, more generally, our model of the economy. For $0 \leq t \leq s$ let $P(t, s)$ be the time $t$-value of a pay-out of one unit of currency at time $s$. Then, for any standard interest rate model, it is true that

$$
B_{t}^{-1} P(t, s) \quad \text { is a } \mathbb{Q} \text {-martingale }
$$

with respect to the filtration underlying the interest rate model. For instance, this holds for short rate models or Libor Market Models. We refer to [11] for more information on interest rate models. In fact, Condition (2.1) is the no-arbitrage condition as in, e.g., [21, Equ. (3.2)]. In terms of simple one-year forward rates $F_{t}$, the bank account is given as the roll-over investment $B_{t}=\Pi_{s=1}^{t}\left(1+F_{s-1}\right)$. The best estimate $B E$ associated to $\mathcal{X}$ is then defined as

$$
B E=E_{\mathbb{Q}}\left[\sum_{t=1}^{T} B_{t}^{-1} \sum_{x \in \mathcal{X}} c f_{x, t}\right]
$$

where $c f_{x, t}$ is the cash-flow at time $t$ generated by contract $x$. The cash flow has to take into account all relevant premia, benefits and costs - see [6, Art. 28].

Let

$$
B V_{t}=B V_{t}(T R)+B V_{t}(S F)
$$

denote the book value of the liability portfolio at time $t$. The liability portfolio is covered by assets whose book value is assumed to equal $B V_{t}$. That is, we make the following simplification:

Assumption 2.2. The company does not have equity in its statutory balance sheet, i.e. with respect to local generally accepted accounting rules.

In other words, Assumption 2.2 requires the book value of assets to be equal to the book value of liablities, which is, of course, a very unrealistic assumption. Its meaning is discussed in Subsection 2.C below where we will see that no generality is lost. We denote the total market value of the company's assets at time $t$ by

$$
M V_{t} \text {. }
$$

The market value of assets $M V_{t}$ will change from one period to the next due to market movements. The same is true, albeit in a more complicated manner, for the book value of assets, $B V_{t}$ : it changes due to coupon payments, dividend yield, etc., as well as due to realization of unrealized gains (whose value depends again on market movements). The precise manner in which this happens depends on the company's management rules and valuation choices such as the lower of cost or market principle. ${ }^{1}$ Regardless of the specific management

\footnotetext{
${ }^{1}$ The lower of cost or market principle, when applied in its strict form, requires a company to depreciate the book value of an asset whenever its market value falls below its current book value. When applied in the
} 
rules and choices, we denote the company's book value return on $B V_{t}$ by

$$
\text { roa }_{t+1}
$$

and emphasize that this is the book value return before corporate tax.

For the next statement we note that we call market value induced changes in book value those changes which follow from the application of valuation principles, such as the lower of cost or market principle, or the realization of unrealized gains.

Criterion 2.1 (Monetary conservation principle). All changes in the book value of assets $B V_{t}$ are either due to a cash-flow or due to a market value induced change in book value.

This property is fundamental. It can be viewed as a no-leakage and self-financing property: up to cash-flows, changes in the book value of the asset portfolio can only be due to interest rate or other (such as: stock) market effects. The above criterion is important in practice as it provides a simple yet challenging validation test for the inspection of real models: see Proposition 2.2.

Let us further elaborate on the no-leakage statement. To this end, we denote by $\operatorname{tax}_{t}$ the corporate tax and by $s h_{t}$ the shareholder gains at $t$. Now, since $c f_{t}=\sum_{x \in \mathcal{X}} c f_{x, t}$ already includes all policy holder and cost cash-flows, the no-leakage criterion amounts to

$$
B V_{t}=B V_{t-1}-c f_{t}-s h_{t}-\operatorname{tax}_{t}+\operatorname{roa}_{t}
$$

Let us define the unexpected return by

$$
u r_{t}:=\operatorname{roa}_{t}-F_{t-1} B V_{t-1}
$$

where

$$
F_{t-1}=\frac{B_{t}}{B_{t-1}}-1
$$

is the simple forward rate from $t-1$ to $t$ implied by the interest rate model.

It follows that

$$
\begin{aligned}
B_{T}^{-1} B V_{T} & =B V_{0}+\sum_{t=1}^{T}\left(B_{t}^{-1} B V_{t}-B_{t-1}^{-1} B V_{t-1}\right) \\
& =B V_{0}+\sum_{t=1}^{T}\left(B_{t}^{-1}\left(B V_{t-1}-c f_{t}-s h_{t}-t a x_{t}+r o a_{t}\right)-B_{t-1}^{-1} B V_{t-1}\right) \\
& =B V_{0}+\sum_{t=1}^{T}\left(\left(B_{t}^{-1}\left(-c f_{t}-s h_{t}-\operatorname{tax}_{t}\right)+B_{t}^{-1}\left(r o a_{t}-F_{t-1} B V_{t-1}\right)\right)\right. \\
& =B V_{0}+\sum_{t=1}^{T}\left(\left(B_{t}^{-1}\left(-c f_{t}-s h_{t}-\operatorname{tax}_{t}\right)+B_{t}^{-1} u r_{t}\right) .\right.
\end{aligned}
$$

mild form, the book value is depreciated only if the market value is expected to remain below its current book value for an extended period of time. 
Taking the expected value with respect to the risk-neutral measure $\mathbb{Q}$, this becomes

$$
B V_{0}+E_{\mathbb{Q}}\left[\sum_{t=1}^{T} B_{t}^{-1} u r_{t}\right]=B E+V I F+T A X+E_{\mathbb{Q}}\left[B_{T}^{-1} B V_{T}\right],
$$

where

$$
V I F=E_{\mathbb{Q}}\left[\sum_{t=1}^{T} B_{t}^{-1} s h_{t}\right]
$$

is the so-called value of in-force business and

$$
T A X=E_{\mathbb{Q}}\left[\sum_{t=1}^{T} B_{t}^{-1} \operatorname{tax}_{t}\right]
$$

is the value of corporate tax payments. The value of in-force business is the model dependent part of the market consistent embedded value $M C E V$ which is generally expressed as

$$
M C E V=V I F+F C_{0},
$$

where $F C_{0}$ is the market value of free capital at time $t=0$. The $M C E V$ is a measure for the shareholder to determine how well the money is invested. Up to required capital and associated frictional costs, this definition coincides with that of [5].

Let us call $U G_{t}:=M V_{t}-B V_{t}$ the unrealized gains.

Proposition 2.2 (Basic equation of market consistent valuation). Let $T$ be the projection horizon. Then

$$
B V_{0}+U G_{0}=B E+V I F+T A X+E_{\mathbb{Q}}\left[B_{T}^{-1} M V_{T}\right]
$$

Moreover, if $B V_{t}(S F)$ is bounded by $B V_{t}(T R)$ then $E_{\mathbb{Q}}\left[B_{T}^{-1} M V_{T}\right] / M V_{0} \approx 0$.

In this statement $\approx$ means equality for all practical valuation purposes. ${ }^{2}$ We remark that there is no advantage in defining the relation $\approx$ in a more mathematical manner. Practically the remainder term $E_{\mathbb{Q}}\left[B_{T}^{-1} M V_{T}\right] / M V_{0}$ should be of the same order as the result of the leakage test, which would be the difference of the two sides of Equation (2.6).

Laimer [16] has verified in her diploma thesis that Equation (2.6) does indeed hold with $E_{\mathbb{Q}}\left[B_{T}^{-1} M V_{T}\right] / A_{0}=0$ up to numerical errors. To do so, she employed a best estimate calculation tool proprietary to the FMA Austria and used several concrete traditional life insurance portfolios.

Proof. Let $\mathcal{A}_{t}$ denote the company's set of assets under management at time $t$. It follows that $u r_{t}=\sum_{a \in \mathcal{A}_{t-1}} u r_{a, t}$ where $u r_{a, t}$ is the contribution stemming from asset $a$ and where the sum

\footnotetext{
${ }^{2}$ As a rule of thumb the relative error should not exceed $1 \%$, otherwise the impact of potential error on own funds would be too large - compare with the sand box example in Table 1.
} 
is over all assets in the portfolio at time $t-1$. Now, for any asset $a \in \mathcal{A}_{0}$, we have

$$
\begin{aligned}
\sum_{t=1}^{T} B_{t}^{-1} u r_{a, t} & =\sum_{t=1}^{T} B_{t}^{-1}\left(c f_{a, t}+a_{t}^{*}-\left(1+F_{t-1}\right) a_{t-1}^{*}\right) \\
& =\sum_{t=1}^{T}\left(B_{t}^{-1} c f_{a, t}+B_{t}^{-1} a_{t}^{*}-B_{t-1}^{-1} a_{t-1}^{*}\right) \\
& =\sum_{t=1}^{T} B_{t}^{-1} c f_{a, t}+B_{T}^{-1} a_{T}^{*}-a_{0}^{*} \\
& =\sum_{t=1}^{T} B_{t}^{-1} c f_{a, t}+B_{T}^{-1} a_{T}-a_{0}^{*}-B_{T}^{-1}\left(a_{T}-a_{T}^{*}\right)
\end{aligned}
$$

where $a_{t}^{*}$ (resp. $a_{t}$ ) is the time $t$ book (resp. market) value of $a$ and $c f_{a, t}$ is the asset's cashflow (coupon, dividend payment, etc.) at $t$. If $a$ has a maturity $T_{a}$ within the projection horizon such that $T_{a} \leq T$, then book and market value coincide at $T_{a}$ such that $a_{T_{a}}=a_{T_{a}}^{*}$, and $c f_{a, t}=a_{t}=a_{t}^{*}=0$ for $T_{a}<t \leq T$. On the other hand, if $T_{a}>T$, then $a_{T}-a_{T}^{*}=U G_{a, T}$ are the unrealized gains of $a$ at time $T$. Because of (2.1) we have

$$
a_{0}=E_{\mathbb{Q}}\left[\sum_{t=1}^{T} B_{t}^{-1} c f_{a, t}+B_{T}^{-1} a_{T}\right],
$$

which implies that

$$
E_{\mathbb{Q}}\left[\sum_{t=1}^{T} B_{t}^{-1} u r_{a, t}\right]=a_{0}-a_{0}^{*}-E_{\mathbb{Q}}\left[B_{T}^{-1}\left(a_{T}-a_{T}^{*}\right)\right]=U G_{a, 0}-E_{\mathbb{Q}}\left[B_{T}^{-1} U G_{a, T}\right] .
$$

Assets that are bought in the course of reinvestment at $t>0$ satisfy $U G_{a, t}=0$, because book value and market value coincide at time of purchase. It follows that

$$
E_{\mathbb{Q}}\left[\sum_{t=1}^{T} B_{t}^{-1} u r_{t}\right]=E_{\mathbb{Q}}\left[\sum_{t=1}^{T} \sum_{a \in \mathcal{A}_{t-1}} B_{t}^{-1} u r_{a, t}\right]=U G_{0}-E_{\mathbb{Q}}\left[B_{T}^{-1} U G_{T}\right],
$$

where $\mathcal{A}_{t}$ denotes the asset portfolio at time $t$, and the result is independent of the particular reinvestment strategy. The statement now follows from (2.5).

2.C. Discussion of assumptions. Assumption 2.1 is very generic. All we need at this point are well-defined book and market values for the liability side of the balance sheet. If the cashflows in Equation (2.2) depend on additional provisions, these should be accordingly added to $B V_{0}$ and $U G_{0}$ in (2.6).

Assumption 2.2 is only at first sight a strong constraint. Actual companies will hold strictly positive equity. The relevant position should be added to the left hand side of (2.6). For the right hand side, however, the statement $E_{\mathbb{Q}}\left[B_{T}^{-1} M V_{T}\right] / M V_{0} \approx 0$ will now not be true anymore. The position $M V_{T}$ will still contain own funds. For actual validation purposes regarding (2.6) it is thus advisable to keep track of equity separately. 


\section{AN ANALYTIC LOWER BOUND FOR FUTURE DISCRETIONARY BENEFITS}

The goal of this section is to derive an analytic, i.e. model-independent, formula for the value of future discretionary benefits. This is achieved under certain assumptions which are discussed in Section 3.D below.

3.A. The lower bound formula. The best estimate can be written as

$$
B E=G B+F D B
$$

where $G B$ stands for guaranteed benefits and is the value of all future cash flows that are already guaranteed at time of calculation $t=0$. Thus $G B$ is independent from all future developments and therefore purely deterministic. In particular, its value is independent of all management actions and economic scenarios. On the other hand, $F D B$ stands for future discretionary benefits and denotes the value of those cash flows that arise via the (future) profit sharing mechanism. Solvency II requires that $F D B$ be determined and reported as a stand-alone part of the best estimate: see [6, Art. 25].

Remark 3.1. We emphasize that this does not mean that the guaranteed benefits are fixed from the policy holder's perspective. In reality, benefits could be influenced by time of surrender, time of death, interest rate movements, tax incentives or other unknown variables. However, the point is that these variables contribute to the guaranteed benefits (as defined by the reporting template [7, Template S.12.01.01]) with their expected values. It is only in this sense, that the guaranteed benefits are model-independent and fixed cash-flows.

The profit sharing mechanism dictates that the collective of policy holders receives a yearly accounting flow $p h_{t}^{*}$.

We make a few generic assumptions: ${ }^{3}$

Assumption 3.1. We assume that the profit sharing mechanism is clearly defined by legislature and stable management rules.

Assumption 3.2. The gross policy holder profit participation rate gph is constant. This is the rate with which the policy holder participates in the company's declared gross surplus $g s^{*}$ (if positive). It does not say anything about the company's return.

We emphasize that $p h_{t}^{*}$ is an accounting flow and not a cash flow. As such it is not paid out to the policy holder at time $t$, but rather increases the book value of liabilities. Observe that

$$
\begin{aligned}
P H^{*} & :=E_{\mathbb{Q}}\left[\sum B_{t}^{-1} p h_{t}^{*}\right] \\
& =g p h E_{\mathbb{Q}}\left[\sum B_{t}^{-1} g s_{+}^{*}(t)\right] \\
& \geq g p h E_{\mathbb{Q}}\left[\sum B_{t}^{-1} g s^{*}(t)\right] \\
& =g p h\left(V I F+P H^{*}+T A X\right)
\end{aligned}
$$

where $s h_{t}, \operatorname{tax}_{t}$ are the respective shareholder, tax cash flows, and $x_{+}=\max (x, 0)$. Here we have used the splitting $g s_{t}^{*}=s h_{t}+p h_{t}^{*}+t a x_{t}$ together with the definitions of $V I F$ and $T A X$

\footnotetext{
${ }^{3}$ We reiterate that we only consider with-profit contracts. All assumptions are discussed in Section 3.D.
} 
from Section 2.B. Note that $s h_{t}$ can be negative, which corresponds to the case of shareholder capital injection.

Assumption 3.3. The policy holder participation $p h_{t}^{*}$ is negatively correlated with discount rate movements; i.e., policy holder participation will generally increase when interest rates increase: $\operatorname{Corr}\left[B_{t}^{-1}, p h_{t}^{*}\right]<0$.

Assumption 3.4. We assume, for the purpose of this section, that the liability book consists of only one contract and that the time to maturity of this contract is $M$.

Assumption 3.5. The technical reserves $T R_{t}$ evolve deterministically. Insurance technical gains are deterministic; i.e., we do not consider stochastic mortality modelling or stochastic (and/or dynamical) surrender behavior.

Notice that the future discretionary benefits received by the policy holder at time of maturity $M$ are exactly the sum $\sum_{t \leq M} p h_{t}^{*}$ of accumulated policy holder profits. This is actually a tricky point and holds only because we assume that policy holder survival probabilities (mortality, surrender, etc.) have already been taken into account. At the same time we do not list this point as an assumption, because it only means that we regard cash flows of surviving policy holders.

Notice that

$$
\begin{aligned}
F D B & =E_{\mathbb{Q}}\left[B_{M}^{-1} \sum_{t \leq M} p h_{t}^{*}\right] \\
& =E_{\mathbb{Q}}\left[B_{M}^{-1}\right] \cdot E_{\mathbb{Q}}\left[\sum_{t \leq M} p h_{t}^{*}\right]+\operatorname{Cov}\left[B_{M}^{-1}, \sum_{t \leq M} p h_{t}^{*}\right] \\
& \geq P(0, M) \cdot E_{\mathbb{Q}}\left[\sum_{t \leq M} p h_{t}^{*}\right]-1 \cdot S D\left[B_{M}^{-1}\right] \cdot S D\left[\sum_{t \leq M} p h_{t}^{*}\right]
\end{aligned}
$$

where $P(0, M)=E_{\mathbb{Q}}\left[B_{M}^{-1}\right]$ is the discount factor at time 0 and we have made use of the fact that the correlation $\operatorname{Corr}\left[B_{M}^{-1}, \sum_{t \leq M} p h_{t}^{*}\right]$ is bounded from below by -1 .

Remark 3.2 (Standard deviation). For a random variable $X$, we shall denote the standard deviation by $S D[X]=\sqrt{E\left[(X-E[X])^{2}\right]}$. In formula (3.9) the standard deviation is understood with respect to the risk neutral measure $\mathbb{Q}$. Often the standard deviation is denoted by $\sigma$ when viewed as a parameter to be inferred from a financial or econometric model. We have chosen the notation $S D[\cdot]$ to reflect the purely statistical approach of Assumption 3.12. Of course, the statistical approach could also be replaced by a parametric model. However, since formula (3.11) depends on the product of two standard deviations, the gain in accuracy of the lower bound (3.12) by using a more refined model to estimate $S D[\cdot]$ is limited.

On the other hand, $\operatorname{Corr}\left[B_{t}^{-1}, p h_{t}^{*}\right]<0$ yields

$$
P H^{*}=E_{\mathbb{Q}}\left[\sum_{t \leq T} B_{t}^{-1} p h_{t}^{*}\right] \leq \sum_{t \leq T} E_{\mathbb{Q}}\left[B_{t}^{-1}\right] \cdot E_{\mathbb{Q}}\left[p h_{t}^{*}\right] \leq \max _{1 \leq t \leq T} P(0, t) \cdot E_{\mathbb{Q}}\left[\sum_{t \leq T} p h_{t}^{*}\right] .
$$

Note that, if forward rates are positive, this maximum is simply $\max _{1 \leq t \leq M} P(0, t)=\left(1+F_{0}\right)^{-1}$. Currently interest rates are negative at the short end. Nevertheless, for the EIOPA curve per year-end 2017 as displayed in Table 8 , the term $\max _{1 \leq t \leq M} P(0, t) \cong 1.005$ is very close to 1 , 
and we will simply set it equal to 1 for better readability and because the error is negligible. The point is, in any case, that this term is deterministic and can be calculated from the initial forward curve.

Proposition 3.3. Let $A_{0}=M V_{0}=B V_{0}+U G_{0}, A_{T}=E_{\mathbb{Q}}\left[B_{T}^{-1} M V_{T}\right]$ and

$$
\eta:=P(0, M) \cdot\left(1-\frac{S D\left[B_{M}^{-1}\right]}{P(0, M)} \cdot \frac{S D\left[\sum_{t<M} p h_{t}^{*}\right]}{E_{\mathbb{Q}}\left[\sum_{t<M} p h_{t}^{*}\right]}\right) \cdot \frac{g p h}{1-g p h}
$$

Then we have the lower bound

$$
F D B \geq \frac{\eta}{1+\eta}\left(A_{0}-A_{T}-G B\right)
$$

Proof. The inequality follows from equations (3.8), (3.9), (3.10) and Proposition 2.2.

3.B. A lower bound formula for various maturities. For the purpose of this section, we shall keep all of the above assumptions except Assumption 3.4. We replace the latter as follows:

Assumption 3.6. Assets are not attributed to individual contracts.

Let $\mathcal{X}$ denote the (finite) set of all contracts in the liability book. For each $x \in \mathcal{X}$ define $\eta_{x}$ according to formula (3.11) with respect to the contract's maturity $M_{x}$. Further, let

$$
D_{x}:=\frac{\eta_{x}}{1+\eta_{x}} .
$$

Recall from Assumption 2.1 that the statutory technical reserves are the sum of the individual reserves, $B V(T R)=\sum_{x \in \mathcal{X}} B V\left(T R^{x}\right)$. Consider

- $A_{0}^{x}:=A_{0} \cdot B V\left(T R^{x}\right) / B V(T R)$, which is a proportional attribution of market values to individual contracts according to the principle $(3.6) ;^{4}$

- $G B^{x}$ denotes the value of guaranteed benefits (at time 0) of contract $x$, and $G B=$ $\sum_{x \in \mathcal{X}} G B^{x}$

- $F D B=\sum_{x \in \mathcal{X}} F D B_{x}$.

Assumption 3.7. Suppose that Proposition 3.3 can be applied to each contract such that

$$
F D B_{x} \geq D_{x}\left(A_{0}^{x}-A_{M_{x}}^{x}-G B^{x}\right) .
$$

Notice that we do not assume $A_{M_{x}}^{x}=0$. This is to allow for cross-financing between contracts, after time $M_{x}$. Define the weights

$$
w_{x}:=\frac{A_{0}^{x}-G B^{x}}{A_{0}-G B}
$$

and the weighted depreciation factor

$$
D:=\sum_{x \in \mathcal{X}} w_{x} D_{x}
$$

\footnotetext{
${ }^{4}$ The attribution can only depend on the book value, since $T R_{x}$ is a statutory reserve and therefore does not have a market value.
} 
It follows that

$$
\begin{aligned}
F D B & =\sum_{x \in \mathcal{X}} F D B_{x} \geq \sum_{x \in \mathcal{X}} D_{x}\left(A_{0}^{x}-A_{M_{x}}^{x}-G B^{x}\right) \\
& =D \sum_{x \in \mathcal{X}}\left(A_{0}^{x}-A_{M_{x}}^{x}-G B^{x}\right)-\sum_{x \in \mathcal{X}}\left(D-D_{x}\right)\left(A_{0}^{x}-A_{M_{x}}^{x}-G B^{x}\right) \\
& =D\left(A_{0}-G B\right)-\sum_{x \in \mathcal{X}} D_{x} A_{M_{x}}^{x}
\end{aligned}
$$

where we use that the weights $w_{x}$ are chosen such that $\sum_{x \in \mathcal{X}}\left(D-D_{x}\right)\left(A_{0}^{x}-G B^{x}\right)=0$. The quantities $A_{M_{x}}^{x}$ correspond to the fraction of $A_{0}^{x}$ which remains in the model after time $M_{x}$. Unfortunately, these quantities are model dependent and are, therefore, a priori unknown. The term $\sum_{x \in \mathcal{X}} D_{x} A_{M_{x}}^{x}$ accounts for the cross-financing. If all of $A_{0}^{x}$ were to be accounted for by a cash-flow up to, and including, time $M_{x}$, then $A_{M_{x}}^{x}=0$.

Proposition 3.4. Assume that there exists $F>0$ such that $\sum_{x \in \mathcal{X}} D_{x} A_{M_{x}}^{x} \leq F$. Then

$$
F D B \geq D\left(A_{0}-G B\right)-F \text {. }
$$

Existence of such an $F$ means that cross-financing is bounded by an a priori estimated quantity F. See Section 3.C for a concrete application of this formula.

3.C. Concrete numbers. Let us apply formula (3.14) to publicly available data from the Allianz Lebensversicherungs AG. Allianz Lebensversicherungs AG is a German life insurance company which has profit sharing contracts in its liability book. The data in Table 2 is taken from the publicly available reports [2] and [1], which concern the accounting year 2017. Hence the applied interest rate information from Table 7 is also with respect to year-end 2017.

Symbol Value Source Name in source

\begin{tabular}{|c|r|l|l|}
\hline$B V_{0}$ & 192.3 & {$[1$, p. 46] } & Versicherung mit Uberschussbeteiligung \\
\hline$U G_{0}$ & 43.2 & {$[2$, p. 46] } & Stille Reserven der einzubeziehenden Kapitalanlagen \\
\hline$S F_{0}$ & 10.4 & {$[1$, p. 52$]$} & Uberschussfonds \\
\hline$G B$ & 154.1 & {$[1$, p. 46] } & Bester Schätzwert: Wert für garantierte Leistungen \\
\hline$F D B$ & 48.6 & {$[1$, p. 46] } & Bester Schätzwert: zukünftige Uberschussbeteiligung \\
\hline
\end{tabular}

TABLE 2. Allianz Lebensversicherungs AG: public data. Values are in billion Euros.

Assumption 3.8. Suppose the weighted depreciation factor (3.13) is equal to the one with maturity $M=15$, so that $D=\eta_{15} /\left(1+\eta_{15}\right)$ with

$$
\eta_{15}:=P(0,15) \cdot\left(1-\frac{S D\left[B_{15}^{-1}\right]}{P(0,15)} \cdot \frac{S D\left[\sum_{t<15} p h_{t}^{*}\right]}{E_{\mathbb{Q}}\left[\sum_{t<15} p h_{t}^{*}\right]}\right) \cdot \frac{g p h}{1-g p h} .
$$

Variations of this assumption are shown in Tables 4 and 5 .

For concrete validation purposes, companies would have the data to explicitly calculate $D$ according to formula (3.13), since $w_{x}$ and $D_{x}$ are quantities which are known a priori.

Assumption 3.9. Assumption 3.2 is made concrete by setting $g p h=0.80$. In Table 3 we shall show results for $g p h=0.75, g p h=0.80$ and $g p h=0.85$. 
Assumption 3.10. Surplus funds are bounded by the technical reserve, i.e., $S F_{t} \leq \theta T R_{t}$ where $\theta>0$ is constant.

Assumption 3.11. The variance of $p h_{t}^{*}$ is not very high, that is, we assume $S D\left[\sum p h_{t}^{*}\right] \cong$ $5 \% \cdot E\left[\sum p h_{t}^{*}\right]$.

Assumption 3.12. Interest rate variance should also be reasonably bounded. When estimated on monthly historical data from year-end 2014 to year 2017 as shown in Table 7, we find, for the coefficient of variation, that $S D\left[B_{15}^{-1}\right] / P(0,15) \cong 4 \%$.

With the discount factor $P(0,15) \cong 84 \%$ from Table 8 , we insert these numbers in $(3.11)$ to obtain

$$
\eta \cong 84 \% \cdot(1-4 \% \cdot 5 \%) \cdot \frac{0.8}{1-0.8} \cong 3.35
$$

and furthermore

$$
L B_{1}:=\frac{\eta}{1+\eta}\left(A_{0}-G B\right) \cong 77 \% \cdot(192.3+43.2-154.1) \cong 62.68
$$

in billion Euros. To compare this number to $F D B=48.6$, we have to subtract two quantities from the lower bound $L B_{1}$ :

(1) According to [13, Art. 91] the surplus fund, $S F_{0}=10.4$, is not part of the Solvency II value of liabilities if this article is authorized by national law. This is the case for Germany (see [3]), whence the surplus fund is to be subtracted from the future discretionary benefits which are calculated by the company (and this deductible is not part of the reported $F D B)$.

(2) The cross-financing term $F$ from Proposition 3.4.

Therefore, the resulting lower bound is

$$
L B=L B_{1}-S F_{0}-F \cong 52.28-F .
$$

To estimate $F$, we have to attribute $A_{0}$ to individual contracts and say something about the cross-financing effects. This information is not publicly available. We therefore separate $A_{0}$ into buckets $A_{0}^{x(t)}$, where $A_{0}^{x(t)}$ belongs to those contracts $x(t)$ which mature at time $t$. Thus contracts are bundled according to their time of maturity. We have to make an assumption concerning the run-off of the portfolio:

Assumption 3.13. The portfolio run-off is roughly geometric, so that the value of reserves is reduced by a factor of $\frac{1}{2}$ every 10 years until the end of the projection. This is formalized as the requirement

$$
\begin{aligned}
A_{0}^{x(t)}: & =\left(2^{-\frac{t-1}{10}}-2^{-\frac{t}{10}}\right) A_{0} \text { for } t=1, \ldots, T-1 \\
A_{0}^{x(T)}: & =2^{-\frac{T-1}{10}} A_{0},
\end{aligned}
$$

and we shall assume that $T=60$.

Notice that $A_{0}=\sum_{x \in \mathcal{X}} A_{0}^{x}=\sum_{t=1}^{60} A_{0}^{x(t)}$ and the corresponding run-off is given by

$$
A_{0}-\sum_{t=1}^{s} A_{0}^{x(t)}=A_{0} \cdot 2^{-s / 10}
$$


for $s<T$.

Furthermore, we have to make an assumption concerning the policy holder cross-financing term $A_{M_{t}}^{t}$ from Proposition 3.4 (where $M_{t}=t$ ). This term has to be a fraction of $A_{0}^{x(t)}$, but this fraction need not be the same for all contracts. For example, it is conceivable that contracts with a low technical interest rate will yield more cross-financing in comparison to contracts with a high technical interest rate. Moreover, the cross-financing effect need not be constant in time.

Assumption 3.14. The cross-financing factor is a decreasing function of time, but does not depend on other contract properties (such as technical interest rate): $A_{t}^{x(t)}=C(t) A_{0}^{x(t)}$ where

$$
C(t)=C_{0} \frac{T-t}{T}
$$

$T=60 ;$ and we will consider $C_{0}=1 \%, C_{0}=3 \%$ and $C_{0}=5 \%$.

With the above assumptions it is possible to calculate the term $F$ from (3.14). Indeed, we set

$$
F=\sum_{x \in \mathcal{X}} D_{x} A_{t}^{x}=C_{0} \sum_{t=1}^{60} \frac{\eta_{x(t)}}{1+\eta_{x(t)}} \frac{T-t}{T} A_{0}^{x(t)}
$$

where

$$
\eta_{x(t)}=P(0, t)\left(1-\frac{S D\left[B_{t}^{-1}\right]}{P(0, t)} \cdot 5 \%\right) \frac{g p h}{1-g p h} .
$$

Now, $P(0, t)$ is taken from Table 8 and $S D\left[B_{t}^{-1}\right]$ is estimated from Table 7 . With $g p h=80 \%$ and $C_{0}=3 \%$ this yields $F \cong 4.1$, whence we obtain the lower bound

$$
L B=L B_{1}-S F_{0}-F \cong € 48.2 b n .
$$

This number should be compared with the value of $F D B=€ 48.6 \mathrm{bn}$ in Table 2. The assumptions leading to (3.21) and, in particular, the choices $M=15, g p h=80 \%$ and $C_{0}=3 \%$ are discussed in Section 3.D. See Section 5 for further choices of $M, g p h$ and $C_{0}$.

3.D. Discussion of assumptions. In the following we shall provide justification for the above assumptions. Nevertheless, we stress that these remain unproved (in the precise mathematical sense) assumptions based on heuristic arguments and expert judgment. For some of the assumptions we can provide a sensitivity analysis in Section 5.

Assumption 3.1 is one that is necessary for any asset liability model that could be employed for best estimate calculation. It is also necessary for our derivation of the lower bound formula. The net policy holder participation fraction shall be denoted by

$$
n p h \text {. }
$$

Under Austrian law $([23, \S 3])$ companies are required to share at least $n p h=85 \%$ of their net profits with policy holders. As the surplus fund belongs to the liability side, this sharing mechanism does not imply that $85 \%$ of net profits are directly declared to specific policy holder accounts. Rather the profits are shared with the surplus fund and then may be used in the future, according to discretionary management rules, to increase policy holder profits. We 
also remark that the situation is very similar in Germany. The Solvency II requirements for realistic modelling of future management actions are given in [6, Art. 23].

Assumption 3.2 means that the profit sharing rate and the corporate tax rate are constant. In Austria this rate is $25 \%$. If this rate is not constant, one would have to use a mean rate to derive the corresponding $g p h$ from $n p h$.

Assumption 3.3 can be seen as a consequence of Solvency II's going concern hypothesis [13, Art. 101]. Indeed, if interest rates go up, one would assume that companies increase their policy holder profit declarations in order to remain a competitive participant in the market.

Assumption 3.4 is only used to derive the preliminary result stated in Proposition 3.3, and is then removed in Section 3.B.

Assumption 3.5 remains unjustified as we do not know of any publicly available data to support it.

Assumption 3.6 means that assets are shared equally among policy holders. For instance, this is the case for Germany $([18, \S 3(1)])$ and Austria $([23, \S 3])$.

Assumption 3.7: Consider a contract $x$ with maturity $M_{x}$. This statement means that we assume the cross-financing between $x$ and other contracts, which occurs before $M_{x}$, can be neglected on average. Alternatively, one could separately consider the cross-financing before time $M_{x}$ and then assume that this cross-financing fully contributes to the $F D B$ in Equation (3.14), whence the lower bound remains unchanged.

Assumption 3.8: To calculate the weighted depreciation factor (3.13), one would need portfolio specific data. According to [14, Fig. A. II.1] the distribution of liability duration for Germany is between 14 and 22 years. Since formula (3.11) includes a discounting term $P(0, t)$, we have chosen $M=15$ to reflect the fact that contributions from later times give rise to a lesser weight. The sensitivity with respect to this assumption is shown in Tables 4 and 5 for $M=10$ and $M=20$, respectively.

Assumption 3.9: German legislature [18, § 4] distinguishes between two different values for the net policy holder participation $n p h$. For most sources of profit $[18, \S 4]$ dictates that $n p h=90 \%$. To arrive at the corresponding gph one has to account for tax payments such that "nph times net profit" equals "gph times gross profit". This assumption thus amounts to using $g p h=80 \%$ as an approximating average factor. ${ }^{5}$ The sensitivity on this assumption is shown in Tables 3, 4 and 5 .

Assumption 3.10 means that gains as well as hidden reserves cannot be kept from the policy holder indefinitely. This assumption is necessary in order to apply Proposition (2.2) with $E_{\mathbb{Q}}\left[B_{T}^{-1} M V_{T}\right]=0$. For modelling purposes, one could apply the following future management action: $S F_{t} \leq \theta M V_{t}(T R)$ where the concrete value of $\theta<1$ is a management rule.

Assumption 3.11 reflects a typical goal of management. In fact, the very purpose of the surplus fund is to keep policy holder participation stable over time. Further, we remark that (3.9) involves a product of two standard deviations. Thus even a higher value for $S D\left[\sum p h_{t}^{*}\right]$ would not have significant impact on the lower bound (3.21). Hence this assumption reflects the assumption that management would try to follow interest rate movements in profit sharing declaration but, at the same time, would try to avoid strong jumps in the declaration.

\footnotetext{
${ }^{5}$ The corresponding Austrian value for gph can be calculated to be $80.75 \%$.
} 
Assumption 3.12 is a consequence of the historical data in Tables 7 and 8. Nevertheless, we have listed this as an assumption since there are many different estimators and time series which one could use to find the coefficient of variation $S D\left[B_{t}^{-1}\right] / P(0, t)$. As with Assumption 3.11, we remark that the sensitivity on this assumption is relatively low, since we are dealing with a product of two standard deviations.

Assumption 3.13 is a formalization of the idea that the portfolio run-off is, roughly, homogeneous in time: according to [2, p. 20] the number of policies in the with-profit business went from approximately 10.5 million to approximately 10 million in the year 2017 (disregarding new business). This is a reduction of about $5 \%$. Now, time-homogeneity in this context should mean that the number of policies will be reduced by a factor of $(1-5 \%)^{t}$ after $t$ years. Thus the run-off is geometric and we take this as a justification for the assumed portfolio reduction (3.18). However, in (3.18) we are concerned with the run-off of technical provisions instead of policy numbers. Therefore, this argument is only a partial justification for (3.18). We stress that companies would have the necessary information in this context, whence Assumption 3.13 would not be needed in real applications (or could be tested against real data).

Assumption 3.14 is related to Assumption 3.10: if we did not assume that the surplus fund was bounded by the decreasing value of technical reserves, then the remainder term $A_{t}^{x(t)}$ could increase the surplus fund at time $t$ and never be converted to a cash-flow. On the other hand, if we allow for an upper bound rule such as Assumption 3.10, then $A_{t}^{x(t)}$ has to decrease with time. A good first approximation for $C_{0}$ could be $S F_{0} / A_{0}=4.4 \%$. We have chosen $C_{0}=3 \%$ to indicate that not all of the cross-financing $A_{t}^{x(t)}$ has to be kept within the surplus fund, but a part may also be directly declared to other policy holders (compare with Assumption 3.7) at times $s \leq t$. Sensitivity on this assumption is shown in Tables 3,4 and 5 .

\section{Discussion of Results}

4.A. The basic equation. Best estimate calculation for with-profit life insurance products is a numerical task. This is due to the fact that there are no closed formula solutions to obtain a best estimate, whence Monte Carlo techniques are employed. This involves, in particular, setting up a full asset liability model such that all relevant cash-flows are generated. The general calculation process is discussed in [17]. Given the degree of sophistication of these asset liability models, one should not expect a closed formula for best estimate calculation.

The virtue of Equation (2.6) is thus that it is a closed formula and has to hold for all asset liability models (that are market consistent and satisfy Assumptions 2.1 and 2.2).

Of course, this does not mean that we can compute the best estimate solely based on Equation (2.6). The terms VIF and TAX are just as hard to compute as BE. The practical value of this equation rather is tied to the fact that it gives a very straightforward validation test for any market consistent best estimate calculation model.

This validation procedure can be viewed as a leakage test. It is a necessary condition for two model properties:

- All cash flows are accounted for - nothing is "lost" by the numerical model.

- The (numerically generated) economic scenarios are free of arbitrage. 
It seems to us that this test is well-known to at least parts of the applied insurance mathematics community as a kind of "folklore wisdom". We remark here that we have found this formula independently. More importantly, we do not know of any literature which explicitly states this formula and, much less, of any references where the assumptions have been spelled out in a rigorous manner.

4.B. The lower bound formula. The best estimate can be expressed as a sum of guaranteed cash flows $G B$ and future discretionary benefits $F D B$. Moreover, it is a Solvency II requirement to report $F D B$ separately as part of the best estimate ([7, Template S.12.01.01]).

The guaranteed benefits depend on second order assumptions concerning, e.g., mortality and surrender but are otherwise completely model-independent. In particular, they do not depend on future management actions or economic scenarios. Indeed, these are fixed cash flows whence they can be valuated deterministically using only the initial risk-free (EIOPA-) interest rate curve. ${ }^{6}$

On the other hand, the calculation of future discretionary benefits $F D B$ involves all the intricacies of best estimate valuation: asset liability model, management rules, economic scenarios, etc. - see [15, 17, 22]. Hence one should not expect a closed forumla solution for the $F D B$. However, the next best thing to a closed formula is a lower bound, and this is what Proposition 3.4 achieves.

Clearly this lower bound cannot be used for reporting purposes, since the true $F D B$ could be considerably larger. We see three important applications for this estimate:

- It can be used by the company as an immediate test for their $F D B$ calculated by means of a numerical asset liabilty model.

- It can be used by the company as a target towards which to optimize the $F D B$ by an appropriate choice of admissible management rules (reinvestment strategy, profit sharing, surplus fund management, etc.)

- It can be used by the regulator as a simple on- or off-site plausibility check for reported $F D B$ s.

All of this works only if the assumptions and generic management rules discussed in Section 3.D are either directly met or suitably amended.

To show how Proposition 3.4 could be used in practice we have, in Section 3.C, applied the lower bound formula to publicly available data of Allianz Lebensversicherung AG [1, 2]. In Equation (3.21) this yields a lower bound of $€ 48.2 \mathrm{bn}$, while the reported number, included in Table 2, is $F D B=€ 48.6 \mathrm{bn}$. The assumptions leading to the result (3.21) are discussed in Section 3.D. Finally, we have included results for the lower bound with respect to variations of some of the key assumptions in Tables 3, 4 and 5 .

\section{Appendix}

Table 7 is used to calculate the standard deviation $S D\left[B_{t}^{-1}\right]$ of the observed discount factor $P(0, t)$ from Table 8. Compare with Remark 3.2.

\footnotetext{
${ }^{6}$ See Remark 3.1.
} 


\begin{tabular}{|c|c|c|c|}
\hline$M=15$ & $g p h=75 \%$ & $g p h=80 \%$ & $g p h=85 \%$ \\
\hline$C_{0}=1 \%$ & 46.9 & 50.9 & 55.7 \\
\hline$C_{0}=3 \%$ & 44.3 & 48.2 & 52.8 \\
\hline$C_{0}=5 \%$ & 41.8 & 45.4 & 49.8 \\
\hline
\end{tabular}

TABLE 3. Lower bound for the FDB. Values are in billion Euros. These results should be compared to the reported value of $F D B=48.6$ from Table 2 .

\begin{tabular}{|c|c|c|c|}
\hline$M=10$ & $g p h=75 \%$ & $g p h=80 \%$ & $g p h=85 \%$ \\
\hline$C_{0}=1 \%$ & 47.7 & 52.5 & 56.5 \\
\hline$C_{0}=3 \%$ & 45.1 & 49.8 & 53.6 \\
\hline$C_{0}=5 \%$ & 42.6 & 47.0 & 50.6 \\
\hline
\end{tabular}

TABLE 4. Lower bound for the $F D B$. Values are in billion Euros. These results should be compared to the reported value of $F D B=48.6$ from Table 2 .

\begin{tabular}{|c|c|c|c|}
\hline$M=20$ & $g p h=75 \%$ & $g p h=80 \%$ & $g p h=85 \%$ \\
\hline$C_{0}=1 \%$ & 44.5 & 49.3 & 54.0 \\
\hline$C_{0}=3 \%$ & 41.9 & 46.6 & 51.1 \\
\hline$C_{0}=5 \%$ & 39.4 & 43.8 & 48.1 \\
\hline
\end{tabular}

TABLE 5. Lower bound for the $F D B$. Values are in billion Euros. These results should be compared to the reported value of $F D B=48.6$ from Table 2 .

\begin{tabular}{|c|c|c|c|}
\hline $\mathrm{F}$ & $C_{0}=1 \%$ & $C_{0}=3 \%$ & $C_{0}=5 \%$ \\
\hline$g p h=75 \%$ & 1.3 & 3.9 & 6.4 \\
\hline$g p h=80 \%$ & 1.4 & 4.1 & 6.9 \\
\hline$g p h=85 \%$ & 1.5 & 4.4 & 7.4 \\
\hline
\end{tabular}

TABLE 6. Values for the cross-financing term $F$. Values are in billion Euros.

\begin{tabular}{|c|c|c|c|c|c|c|c|c|c|}
\hline $\mathbf{1 2} / \mathbf{2 0 1 4}$ & $\mathbf{0 1 / 2 0 1 5}$ & $\mathbf{0 2 / 2 0 1 5}$ & $\mathbf{0 3 / 2 0 1 5}$ & $\mathbf{0 4 / 2 0 1 5}$ & $\mathbf{0 5 / 2 0 1 5}$ & $\mathbf{0 6 / 2 0 1 5}$ & $\mathbf{0 7 / 2 0 1 5}$ & $\mathbf{0 8 / 2 0 1 5}$ & $\mathbf{0 9 / 2 0 1 5}$ \\
\hline $1.08 \%$ & $0.85 \%$ & $0.88 \%$ & $0.63 \%$ & $0.78 \%$ & $1.06 \%$ & $1.43 \%$ & $1.26 \%$ & $1.40 \%$ & $1.27 \%$ \\
\hline
\end{tabular}

\begin{tabular}{|c|c|c|c|c|c|c|c|c|c|}
\hline $\mathbf{1 0 / 2 0 1 5}$ & $\mathbf{1 1 / 2 0 1 5}$ & $\mathbf{1 2 / 2 0 1 5}$ & $\mathbf{0 1 / 2 0 1 6}$ & $\mathbf{0 2 / 2 0 1 6}$ & $\mathbf{0 3 / 2 0 1 6}$ & $\mathbf{0 4 / 2 0 1 6}$ & $\mathbf{0 5 / 2 0 1 6}$ & $\mathbf{0 6 / 2 0 1 6}$ & $\mathbf{0 7 / 2 0 1 6}$ \\
\hline $1.22 \%$ & $1.21 \%$ & $1.34 \%$ & $0.98 \%$ & $0.75 \%$ & $0.82 \%$ & $0.98 \%$ & $0.84 \%$ & $0.66 \%$ & $0.50 \%$ \\
\hline
\end{tabular}

\begin{tabular}{|c|c|c|c|c|c|c|c|c|c|}
\hline $\mathbf{0 8 / 2 0 1 6}$ & $\mathbf{0 9 / 2 0 1 6}$ & $\mathbf{1 0 / 2 0 1 6}$ & $\mathbf{1 1 / 2 0 1 6}$ & $\mathbf{1 2 / 2 0 1 6}$ & $\mathbf{0 1 / 2 0 1 7}$ & $\mathbf{0 2 / 2 0 1 7}$ & $\mathbf{0 3 / 2 0 1 7}$ & $\mathbf{0 4 / 2 0 1 7}$ & $\mathbf{0 5 / 2 0 1 7}$ \\
\hline $0.52 \%$ & $0.54 \%$ & $0.78 \%$ & $0.96 \%$ & $0.96 \%$ & $1.15 \%$ & $0.99 \%$ & $1.08 \%$ & $1.10 \%$ & $1.12 \%$ \\
\hline
\end{tabular}

\begin{tabular}{|c|c|c|c|c|c|c|}
\hline $\mathbf{0 6 / 2 0 1 7}$ & $\mathbf{0 7 / 2 0 1 7}$ & $\mathbf{0 8 / 2 0 1 7}$ & $\mathbf{0 9 / 2 0 1 7}$ & $\mathbf{1 0 / 2 0 1 7}$ & $\mathbf{1 1 / 2 0 1 7}$ & $\mathbf{1 2 / 2 0 1 7}$ \\
\hline $1.22 \%$ & $1.29 \%$ & $1.13 \%$ & $1.26 \%$ & $1.18 \%$ & $1.17 \%$ & $1.18 \%$ \\
\hline
\end{tabular}

TABle 7. Euro base curve, 15-year spot rates. Source: [10]. 


\begin{tabular}{|c|c|}
\hline $\mathbf{t}$ & $P_{0, t}$ \\
\hline 1 & 1.004 \\
\hline 2 & 1.005 \\
\hline 3 & 1.003 \\
\hline 4 & 0.997 \\
\hline 5 & 0.990 \\
\hline 6 & 0.979 \\
\hline 7 & 0.968 \\
\hline 8 & 0.954 \\
\hline 9 & 0.940 \\
\hline 10 & 0.923 \\
\hline
\end{tabular}

\begin{tabular}{|c|c|}
\hline $\mathbf{t}$ & $P_{0, t}$ \\
\hline 11 & 0.906 \\
\hline 12 & 0.889 \\
\hline 13 & 0.872 \\
\hline 14 & 0.855 \\
\hline 15 & 0.839 \\
\hline 16 & 0.824 \\
\hline 17 & 0.810 \\
\hline 18 & 0.795 \\
\hline 19 & 0.780 \\
\hline 20 & 0.764 \\
\hline
\end{tabular}

\begin{tabular}{|c|c|}
\hline $\mathbf{t}$ & $P_{0, t}$ \\
\hline 21 & 0.746 \\
\hline 22 & 0.726 \\
\hline 23 & 0.706 \\
\hline 24 & 0.685 \\
\hline 25 & 0.664 \\
\hline 26 & 0.643 \\
\hline 27 & 0.622 \\
\hline 28 & 0.601 \\
\hline 29 & 0.580 \\
\hline 30 & 0.559 \\
\hline
\end{tabular}

\begin{tabular}{|c|c|}
\hline $\mathbf{t}$ & $P_{0, t}$ \\
\hline 31 & 0.539 \\
\hline 32 & 0.519 \\
\hline 33 & 0.500 \\
\hline 34 & 0.481 \\
\hline 35 & 0.463 \\
\hline 36 & 0.446 \\
\hline 37 & 0.428 \\
\hline 38 & 0.412 \\
\hline 39 & 0.396 \\
\hline 40 & 0.381 \\
\hline
\end{tabular}

\begin{tabular}{|c|c|}
\hline $\mathbf{t}$ & $P_{0, t}$ \\
\hline 41 & 0.366 \\
\hline 42 & 0.351 \\
\hline 43 & 0.337 \\
\hline 44 & 0.324 \\
\hline 45 & 0.311 \\
\hline 46 & 0.299 \\
\hline 47 & 0.287 \\
\hline 48 & 0.276 \\
\hline 49 & 0.265 \\
\hline 50 & 0.254 \\
\hline
\end{tabular}

\begin{tabular}{|c|c|}
\hline $\mathbf{t}$ & $P_{0, t}$ \\
\hline 51 & 0.244 \\
\hline 52 & 0.234 \\
\hline 53 & 0.225 \\
\hline 54 & 0.216 \\
\hline 55 & 0.207 \\
\hline 56 & 0.199 \\
\hline 57 & 0.191 \\
\hline 58 & 0.183 \\
\hline 59 & 0.176 \\
\hline 60 & 0.169 \\
\hline
\end{tabular}

TABle 8. Euro discount rates at 31.12.2017. Source: [10].

\section{REFERENCES}

[1] Allianz Lebensversicherungs AG, Bericht über Solvabilität und Finanzlage 2017: https://www.allianzdeutschland.de/berichte-ueber-solvabilitaet-und-finanzlage

[2] Allianz Lebensversicherungs AG, Geschäftsbericht 2017: https://www. allianzdeutschland.de/geschaeftsberichte

[3] BaFin Auslegungsentscheidungen, Überschussfonds nach Art. 91 der Solvency II Richtlinie, https://www.bafin.de/SharedDocs/Downloads/DE/Auslegungsentscheidung/dl_ae_151204_ueberschussfonds.h

[4] Bundesgesetz über den Betrieb und die Beaufsichtigung der Vertragsversicherung (Versicherungsaufsichtsgesetz 2016 - VAG 2016)

[5] CFO Forum, Market Consistent Embedded Value Principles - April 2016. Downloaded from http://www.cfoforum.nl/embedded_value.html

[6] Commission Delegated Regulation (EU) 2015/35 of 10 October 2014 supplementing Directive 2009/138/EC of the European Parliament and of the Council on the taking-up and pursuit of the business of Insurance and Reinsurance (Solvency II).

[7] Commission Implementing Regulation (EU) 2015/2450 of 2 December 2015 laying down implementing technical standards with regard to the templates for the submission of information to the supervisory authorities according to Directive 2009/138/EC of the European Parliament and of the Council

[8] L. Delong, Practical and theoretical aspects of market-consistent valuation and hedging of insurance liabilities, Bank i Kredyt, Narodowy Bank Polski, vol. 42(1) (2011), pages 49-78.

[9] EIOPA Statistics, https://eiopa.europa.eu/Pages/Financial-stability-and-crisis-prevention/Insurance-S

[10] EIOPA, Risk-free interest rate term structure: https://eiopa.europa.eu/regulation-supervision/insurance/sol

[11] D. Filipovic, Term-Structure Models, Springer Finance Textbooks, 2009.

[12] H. Gerber, Life insurance mathematics, Springer 1997.

[13] Directive 2009/138/EC of the European Parliament and of the Council of 25 November 2009 on the taking-up and pursuit of the business of Insurance and Reinsurance (Solvency II).

[14] EIOPA-BoS-16/302, 2016 EIOPA Insurance Stress Test Report.

[15] Kemp, M. Market Consistency: Model Calibration in Imperfect Markets, Wiley 2009.

[16] K. Laimer, Zinsszenarien und Best Estimate in der Lebensversicherung, Diploma Thesis, TU Vienna, 2015.

[17] Laurent, J.-P., Norberg, R., and Planchet, F., Modelling in Life Insurance A Management Perspective, EAA Series (2016), Springer International Publishing.

[18] Mindestzuführungsverordnung (MindZV): http://www . buzer. de/s2.htm?ag=12013\&loc=2\&v=MindZV

[19] C. O'Brien, Valuation of Life Insurance Liabilities on a Market-Consistent Basis: Experience from the United Kingdom, Actuarial Practice Forum (2009).

[20] T. Sheldon, A. Smith, Market Consistent Valuation of Life Assurance Business, British Actuarial Journal 10(3) (2004), 543-605. 
[21] J. Teichmann, M. Wüthrich, Consistent long-term yield prediction, arXiv:1203.2017.

[22] J. Vedani, N. El Karoui, S. Loisel, J.-L. Prigent, Market inconsistencies of market-consistent European life insurance economic valuations: pitfalls and practical solutions, Eur. Actuar. J. 7 (2017).

[23] Verordnung der Finanzmarktaufsichtsbehörde (FMA) über die Gewinnbeteiligung in der Lebensversicherung.

Austrian Financial Market Authority (FMA), Otto-Wagner Platz 5, A-1090 Vienna

E-mail address: simon.hochgerner@gmail.com

E-mail address: florian.gach@gmail.com 